\title{
An unusual case of impacted biliary stone
}

The incidence of biliary stones is higher in the female sex $[1,2]$. Common bile duct (CBD) stones are the most common cause of acute biliary pancreatitis (ABP) [3]. We report the case of a 39-year-old woman with $\mathrm{ABP}$.

The patient underwent endoscopic retrograde cholangiopancreatography (ERCP) with an initial approach to the minor papilla, which looked like the major papilla. During ERCP we observed an impacted biliary stone in the papilla ( Fig. 1; Video 1). Pre-cut was performed resulting in spontaneous stone expulsion, but it was not possible to gain access to the CBD. The contrast medium injection revealed a dilated Santorini duct originating from the cut papilla. The junction between the Santorini and the Wirsung duct was far from the minor papilla, in the $3 \mathrm{rd}$ duodenal portion, with an abnormal biliopancreatic junction, and an uncommon intramural channel > 15 mm (> Fig. 2 ).

After pancreatography, a wire was advanced into the Santorini duct, through the Wirsung duct, to the duodenum, across the major papilla. After the "inverted rendezvous," a septotomy was performed, which enabled CBD access, and then endoscopic biliary sphincterotomy (EBS) was performed. The cholangiography showed a $10 \mathrm{~mm}$ diameter CBD with multiple fragmented stones in the distal portion. The fragments were extracted using a Dormia basket, and a $7 \mathrm{Fr} \times 5 \mathrm{~cm}$ pancreatic plastic stent was placed for the prevention of post-ERCP acute pancreatitis ( $\triangleright$ Video 1 ).

Endoscopy_UCTN_Code_TTT_1AR_2AH

Competing interests

None

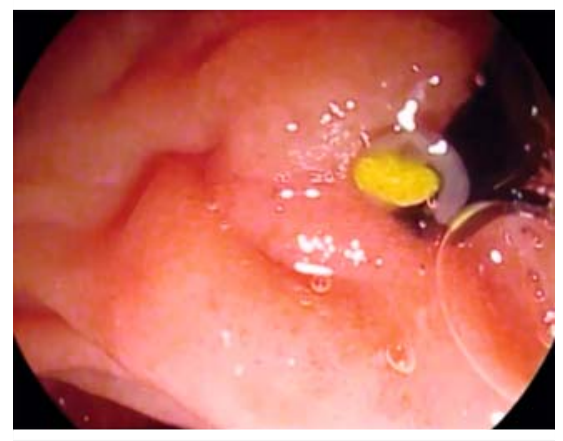

Fig. 1 The impacted biliary stone in the minor papilla.

The Authors

Massimiliano Mutignani ${ }^{1}$, Lorenzo

Dioscoridi ${ }^{1}$, Edoardo Forti ${ }^{1}$, Francesco

Pugliese $^{1}$, Stephen Dokas ${ }^{2}$, Alberto Tringali ${ }^{1}$, Benedetto Mangiavillano ${ }^{3}$

1 Digestive Endoscopy Unit, Niguarda-Ca' Granda Hospital, Milan, Italy

2 Endoscopy Department, St Lukes Hospital, Thessaloniki, Greece

3 Gastrointestinal Endoscopy Unit, Humanitas Mater Domini - Castellanza (VA), Italy

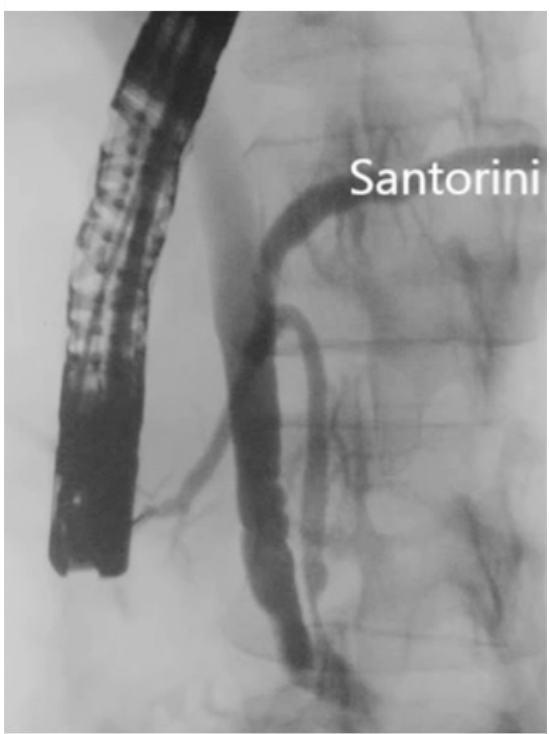

Fig. 2 Radiographic features of the pancreatobiliary junction far from the minor papilla, in the $3 \mathrm{rd}$ duodenal portion, with an uncommon intramural channel.

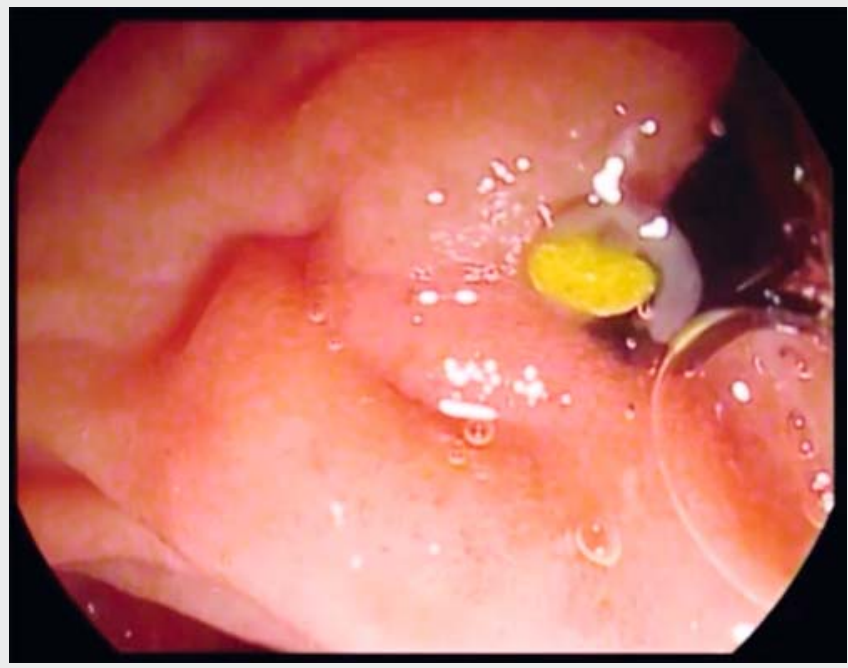

$\checkmark$ Video 1 The "inverted rendezvous" and major papilla septotomy to gain access to the common bile duct, followed by endoscopic biliary sphincterotomy and retrieval of multiple stone fragments. 


\section{Massimiliano Mutignani, MD}

Digestive and Interventional Endoscopy Unit, Ospedale Ca' Granda Niguarda, Piazza dell'Ospedale Maggiore 3, 20162 Milano, Italy

Fax: +39-2-64442911

massimiliano.mutignani@ospedaleniguarda.

\section{References}

[1] Appelros S, Borgström A. Incidence, aetiology and mortality rate of acute pancreatitis over 10 years in a defined urban population in Sweden. Br J Surg 1999; 86: 465 -470
[2] Frey CF, Zhou H, Harvey DJ et al. The incidence and case-fatality rates of acute biliary, alcoholic, and idiopathic pancreatitis in California, 1994-2001. Pancreas 2006; 33: $336-344$

[3] Chen Y, Zak Y, Hernandez-Boussard T et al. The epidemiology of idiopathic acute pancreatitis, analysis of the nationwide inpatient sample from 1998 to 2007. Pancreas 2013; 42: $1-5$

\section{Bibliography}

DOI https://doi.org/10.1055/s-0043-109234

Published online: 29.6.2017

Endoscopy 2017; 49: E208-E209

(c) Georg Thieme Verlag KG

Stuttgart · New York

ISSN 0013-726X
ENDOSCOPY E-VIDEOS

https://eref.thieme.de/e-videos

口回 Endoscopy E-Videos is a free access online section, reporting 田: on interesting cases and new techniques in gastroenterological endoscopy. All papers include a high quality video and all contributions are freely accessible online.

This section has its own submission website at

https://mc.manuscriptcentral.com/e-videos 